prognosis. Absent pupillary light reflexes, absence of corneal reflexes, and caloric or doll's-eye reflexes when observed on admission were each associated with a less than one chance in 20 of independent recovery. No patient recovered who still lacked pupillary reflexes, corneal reflexes, or motor responses to pain or who showed an extensor posture after three days. At the end of the first day an independent recovery is predictable in patients who speak any words, open their eyes in response to noise, have orientating spontaneous eye movements, show nystagmus on caloric testing, have normal doll's-eye responses, and obey commands. Similar responses at three days were followed by independent recovery in over two-thirds of patients.

Clearly, therefore, persisting coma and abnormal neuroophthalmological signs, even at 24 hours, forecast a bad prognosis. Anaesthetic, muscle relaxant, and sedative drugs must be eliminated with absolute certainty before any prognostic assessment is made. Many of the important signs may require a certain amount of neurological skill to elicit and interpret.

The results parallel those obtained in patients with head injuries, ${ }^{3}$ though there are differences, particularly in respect of age, which worsens the outlook more for the patient with a head injury than for non-traumatic coma. What about other investigations: CT scanning, electroencephalography, angiography? These tests have their place in showing the cause of coma in some patients but they are less valuable than clinical indices in pointing to functional recovery. ${ }^{2}$ All neurologists have experience of patients in deepest coma, with normal cerebrospinal fluid, CT scans, and angiographic findings. The clinical art is not yet dead-in one sphere at least. Yet, valuable as clinical information may be, these diagnostic methods are valueless unless interpreted with precision.

This new information will facilitate early prognosis and management and should help to concentrate resources where they are most needed. Nevertheless, the extent of observer variation is not yet known, though in trained medical hands it should be small. What are now needed are prospective studies applying these criteria to patients in coma of every type.

1 Bates D, Caronna JJ, Cartlidge NEF, et al. A prospective study of nontraumatic coma: methods and results in 310 patients. Ann Neurol 1977; ii :211-20.

2 Levy DE, Bates D, Caronna JJ, et al. Prognosis in nontraumatic coma. Ann Intern Med $1981 ; 94: 293-301$.

3 Jennett B, Teasdale G, Braakman R, Minderboud J, Heiden J, Kurze T. Prognosis of patients with severe head injury. Neurosurgery $1979 ; 4$ 283-9.

\title{
Occupational health should not accept tobacco industry sponsorship
}

Tobacco industry sponsorship of sport, opera, and the visual arts is objectionable enough, but when it comes to the industry providing money for the Institute of Occupational Health things have gone too far. Yet the Financial Times of 12 June carried a half-page advertisement appealing for $£ 2 \frac{1}{2} \mathrm{~m}$ for the institute, and listed among the companies that have contributed already was Imperial Tobacco. ${ }^{1}$ Included in the advertisement ironically is a chest radiograph showing advanced silicosis: the radiograph could equally well have shown a carcinoma caused by cigarette smoking.

Smoking is an important cause of work-associated illness. As the recent Royal College of Physicians' report on disabling chest disease says: "As compared to the occupational dusts and vapours, smoking is a major cause of respiratory disablement in workers in many industries."2 The report also notes the enhanced risk of lung cancer in asbestos workers who smoke. It is difficult to untangle the relative importance of cigarette smoke and other pollutants and dusts in causing occupational lung disease, but undoubtedly cigarette smoke is important-as it is in causing occupational heart disease. ${ }^{3}$ Another way in which smoking contributes to occupational disease is through fires: $20 \%$ of fires in industrial premises in 1974 were definitely associated with smoking materials. ${ }^{4}$ Furthermore, research by Hirayama ${ }^{5}$ and others ${ }^{6}$ suggests that a man smoking at work may be endangering not only himself but his mate next to him. This association provides scientific support to those $\mathbf{7 4} \%$ of people (and, interestingly, $67 \%$ of smokers) who in a National Opinion Poll survey conducted last year said that they thought that all workers should be able to work in a smoke-free environment.
The advertisement in the Financial Times notes that 358 million working days were lost last year through illness, but it does not say that 50 million of them were lost because of smoking-associated diseases. Well over half of working men in social classes IV and V smoke, and in the last decade there has been nothing like the same decline in smoking among these men as in social classes I and II. Occupational physicians are well placed to improve these miserable figures. In the United States, where the National Interagency Council on Smoking and Health estimates that smoking costs 12 to 18 billion dollars a year through lost productivity, some $15 \%$ of businesses have programmes to help their employees to stop smoking.

The Institute of Occupational Health is still at an early stage in its development. Its aims deserve generous support from individuals and corporate bodies, but the enthusiasm of the fund raisers should be tempered by discretion. The $B M F$ believes that no medical body should accept money from the tobacco industry, and that the Institute of Occupational Health should recognise its mistake and sever the connection.

\footnotetext{
${ }^{1}$ Institute of Occupational Health. Advertisement. Financial Times 1981; June 12:7.

${ }^{2}$ Royal College of Physicians Committee on Thoracic Medicine. Disabling chest disease: prevention and care. London: RCP, 1981.

3 Engel HO. Is smoking an occupational risk ? f $R$ Soc Med 1981 ;74:73-4.

4 Home Office. United Kingdom fire statistics 1974. London: Home Office, 1978.

${ }^{5}$ Hirayama T. Non-smoking wives of heavy smokers have a higher risk of lung cancer: a study from Japan. $B r$ Med $\mathcal{f} 1981$;282:183-5.

${ }^{6}$ Trichopoulos D, Kalandili A, Sparros L, MacMahon B. Lung cancer and passive smoking. Int $\mathcal{f}$ Cancer 1981 ;282:183-5.
} 